\title{
BMJ Open Glycated haemoglobin A1c is associated with low-grade albuminuria in Chinese adults
}

Xiaolin Huang, ${ }^{1,2}$ Yulin Zhou, ${ }^{1,2}$ Baihui Xu, ${ }^{1,2}$ Wanwan Sun, ${ }^{1,2}$ Lin Lin, ${ }^{1,2}$
Jichao Sun, ${ }^{1,2}$ Min Xu, ${ }^{1,2}$ Jieli Lu, ${ }^{1,2}$ Yufang Bi, ${ }^{1,2}$ Weiqing Wang, ${ }^{1,2}$ Yu Xu, ${ }^{1,2}$
Guang Ning

\section{ABSTRACT}

Background and objective: Diabetes is a strong risk Xu B, et al. Glycated haemoglobin A1c is associated with low-grade albuminuria in Chinese adults. BMJ Open 2015;5: e007429. doi:10.1136/ bmjopen-2014-007429

- Prepublication history for this paper is available online. To view these files please visit the journal online (http://dx.doi.org/10.1136/ bmjopen-2014-007429).

$\mathrm{XH}$ and $\mathrm{YZ}$ contributed equally.

Received 11 December 2014 Revised 10 June 2015 Accepted 3 July 2015

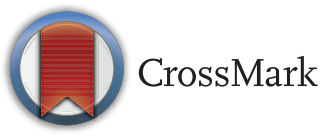

\footnotetext{
${ }^{1}$ Key Laboratory for Endocrine and Metabolic Diseases of Ministry of Health, Rui-Jin Hospital, Shanghai Jiao-Tong University School of Medicine, E-Institute of Shanghai Universities, Shanghai, China

${ }^{2}$ Shanghai Clinical Center for Endocrine and Metabolic Diseases, Shanghai Institute of Endocrine and Metabolic Diseases, Department of Endocrine and Metabolic Diseases, Rui-Jin Hospital, Shanghai Jiao-Tong University School of Medicine, Shanghai, China
}

Correspondence to Dr Yu Xu; jane.yuxu@gmail.com factor for cardiovascular diseases, whereas few studies have investigated simultaneously the associations of glycated haemoglobin $\mathrm{A} 1 \mathrm{c}(\mathrm{HbA} 1 \mathrm{c})$, fasting blood glucose (fasting plasma glucose (FPG)) and $2 \mathrm{~h}$ postload blood glucose (2 h PG) with low-grade albuminuria, which is an earlier marker of cardiovascular diseases in the general population. Our study aimed to investigate and compare associations of $\mathrm{HbA1c}, \mathrm{FPG}$, and $2 \mathrm{~h}$ PG levels with risks of low-grade albuminuria in the middle-aged and elderly Chinese.

Design and methods: This was a cross-sectional study involving 9188 participants aged 40 years or older. All participants underwent a standard $75 \mathrm{~g}$ oral glucose tolerance test. Low-grade albuminuria was defined as the highest quartile of urinary albumin-tocreatinine ratio (ACR) $(>6.10 \mathrm{mg} / \mathrm{g}$ in males and $>8.76 \mathrm{mg} / \mathrm{g}$ in females) in respondents without microalbuminuria or macroalbuminuria.

Results: HbA1c, FPG and $2 \mathrm{~h}$ PG were all significantly correlated with urinary ACR after adjustment for confounders (all $p$ values $<0.0001$ ). After adjustment for $\mathrm{HbA1c}$, the relationships of FPG and $2 \mathrm{~h} \mathrm{PG}$ with ACR reduced to null. $\mathrm{HbA1c}$ levels were still significantly associated with ACR after further adjustment for FPG and $2 \mathrm{~h}$ PG. Multiple logistic regression showed that risks of low-grade albuminuria were positively associated with $\mathrm{HbA1c}$ levels in a doseresponse manner. Compared with participants with $\mathrm{HbA} 1 \mathrm{c} \leq 37 \mathrm{mmol} / \mathrm{mol}(5.5 \%)$, ORs (95\% Cls) for lowgrade albuminuria were 1.05 (0.94 to 1.18), 1.25 (1.04 to 1.50$), 1.40$ (1.04 to 1.90$)$ and 2.21 (1.61 to 3.03 ) for $\mathrm{HbA} 1 \mathrm{c}$ categories of $38-42 \mathrm{mmol} / \mathrm{mol}(5.6-6.0 \%)$, $43-48 \mathrm{mmol} / \mathrm{mol}(6.1-6.5 \%), 49-53 \mathrm{mmol} / \mathrm{mol}(6.6-$ $7.0 \%)$, and $>53 \mathrm{mmol} / \mathrm{mol}(7.0 \%)$, respectively $\left(\mathrm{p}_{\text {for trend }}<0.0001\right)$.

Conclusions: $\mathrm{HbA} 1 \mathrm{c}$, but not FPG or $2 \mathrm{~h} P \mathrm{PG}$, was independently associated with an increased risk of lowgrade albuminuria in the middle-aged and elderly Chinese.

\section{INTRODUCTION}

The presence of microalbuminuria, which is defined as urinary albumin-to-creatinine ratio

\section{Strengths and limitations of this study}

- The current study is a large community-based study in a general Chinese population, which explored the association between three glycaemic indicators and low-grade albuminuria.

- This might be the first study to compare the associations among glycated haemoglobin A1C $(\mathrm{HbA1c})$, fasting plasma glucose and $2 \mathrm{~h}$ postload glucose (2 h PG) with low-grade albuminuria.

- The cross-sectional nature of this study limited us to conclude a causal relationship between $\mathrm{HbA1C}$ and low-grade albuminuria.

- Urinary albumin excretion assessed from a single urine sample was also an important limitation of this study.

(ACR) between $30 \mathrm{mg} / \mathrm{g}$ and $299 \mathrm{mg} / \mathrm{g}$, predicts the progression of chronic kidney disease or nephropathy in patients with diabetes. ${ }^{1}$ In addition, it is well recognised that microalbuminuria is an important risk factor for cardiovascular diseases. ${ }^{2-5}$ However, accumulating evidence has shown recently that low-grade albuminuria, an earlier stage with urinary ACR below the microalbuminuria threshold, is also associated with increased risk of cardiovascular morbidity and mortality. $^{6-8}$ The Heart Outcomes Prevention Evaluation found a continuous association between levels of urinary ACR and cardiovascular events. Major cardiovascular events increased by $5.9 \%$ for every $3.0 \mathrm{mg} / \mathrm{g}$ increase in urinary ACR, starting at the urinary ACR level of $4.4 \mathrm{mg} / \mathrm{g}^{2}$

Diabetes is a strong, independent risk factor for cardiovascular diseases. The relative risk of cardiovascular diseases in those with diabetes is approximately twice the level seen in those without diabetes. ${ }^{9}$ Although glycated haemoglobin A1c (HbA1c), which was integrated into the diagnostic criteria for diabetes by the American Diabetes 
Association in 2010, has been demonstrated to be associated with cardiovascular diseases in observational studies, ${ }^{10}$ evidence from randomised controlled trials is not consistent regarding HbAlc reduction and macrovascular outcomes. ${ }^{11} 12$ Moreover, few studies have examined the association between HbAlc concentrations and low-grade albuminuria, an early marker of cardiovascular diseases, or compared the associations with low-grade albuminuria among HbAlc, fasting plasma glucose (FPG) and $2 \mathrm{~h}$ postload glucose (2 h PG) .

Hence, this study examined the association between low-grade albuminuria and HbAlc with comparisons to FPG and $2 \mathrm{~h}$ PG in the middle-aged and elderly Chinese.

\section{MATERIALS AND METHODS \\ Study population}

This was a community-based cross-sectional study, which recruited residents aged 40 years or older from Jiading District, Shanghai, China from March to August 2010. The study design and protocol were described previously. ${ }^{13}{ }^{14}$ A total of 10375 respondents participated in this survey. The prevalence of microalbuminuria (ACR $30-299 \mathrm{mg} / \mathrm{g}$ ) was $6.3 \%$ and that of macroalbuminuria (ACR $\geq 300 \mathrm{mg} / \mathrm{g}$ ) was $0.5 \%$. We excluded participants with self-reported histories of renal diseases including glomerulonephritis, nephritic syndrome, malignancy, gouty nephropathy and lupus nephritis $(n=492)$; participants with estimated glomerular filtration rate (eGFR) $<15 \mathrm{~mL} / \mathrm{min} / 1.73 \mathrm{~m}^{2}(\mathrm{n}=5)$; participants with missing information on FPG, $2 \mathrm{~h}$ PG, HbA1c or urinary ACR $(n=69)$; and participants with microalbuminuria $(n=580)$ or macroalbuminuria $(n=41)$. Therefore, a total of 9188 participants were included in the current analysis.

\section{Data collection}

Detailed information on sociodemographics, medical history and lifestyle was acquired using a standard questionnaire completed by trained physicians using a face-to-face interview. Current smoker was defined as someone who smoked one cigarette per day or seven cigarettes per week in the past 6 months. Current drinker was defined as someone who consumed alcohol once a week over the past 6 months. Levels of physical activity including leisure time and work-related physical activity were categorised as low, moderate and high, based on the short form of the International Physical Activity Questionnaire (IPAQ). ${ }^{15}$

Anthropometric characteristics were measured by trained personnel according to a standard protocol. Height and weight were measured without shoes and in lightweight clothing to the nearest $0.1 \mathrm{~cm}$ and $0.1 \mathrm{~kg}$, respectively. Body mass index (BMI) was calculated by weight (kilograms) divided by squared height (metres). Obesity was defined as a $\mathrm{BMI} \geq 30 \mathrm{~kg} / \mathrm{m}^{2}{ }^{16}$ Blood pressure was measured on the non-dominant arm by an automated electronic device (OMRON Model HEM-752,
FUZZY, Omron Company, Dalian, China) three times with a 1 min interval in a sitting position after 5 min rest. Three readings were averaged for analysis. Hypertension was defined by systolic blood pressure (SBP) $\geq 140 \mathrm{~mm} \mathrm{Hg}$ and/or diastolic blood pressure (DBP) $\geq 90 \mathrm{~mm} \mathrm{Hg}$ and/or use of antihypertensive medications.

\section{Biochemical evaluation}

Venous blood samples were collected following an overnight fast of at least $10 \mathrm{~h}$. A standard $75 \mathrm{~g}$ oral glucose tolerance test (OGTT) was performed and $2 \mathrm{~h}$ PG samples were also collected. Blood glucose levels were measured using the glucose oxidase method on an autoanalyzer (Modular P800; Roche, Basel, Switzerland). Total cholesterol, low-density lipoprotein cholesterol (LDL-c), highdensity lipoprotein cholesterol (HDL-c), triglycerides (TG) and serum creatinine were also measured on the autoanalyzer (Modular E170; Roche, Basel, Switzerland). HbAlc was determined by high-performance liquid chromatography (BIO-RAD D-10, USA). Diabetes was diagnosed according to the 1999 WHO criteria, that is, an FPG $\geq 7.0 \mathrm{mmol} / \mathrm{L}$, and/or $2 \mathrm{~h} \mathrm{PG} \geq 11.1 \mathrm{mmol} / \mathrm{L}$, and or a self-reported previous diagnosis by physicians. The index of homoeostasis model assessment of insulin resistance (HOMA-IR) was calculated by the formula: HOMA$\mathrm{IR}=$ fasting insulin concentrations $(\mathrm{mIU} / \mathrm{L}) \times$ fasting glucose concentrations $(\mathrm{mmol} / \mathrm{L}) / 22.5 .{ }^{14}$ eGFR was calculated using the abbreviated modification of diet in renal disease (MDRD) formula recalibrated for the Chinese: $\quad$ eGFR $=186 \times(\text { serum } \quad \text { creatinine } \times 0.011)^{-1.154} \times$ $(\text { age })^{-0.203} \times(0.742$ if female $) \times 1.233$, where serum creatinine is expressed in $\mu \mathrm{mol} / \mathrm{L}$ and 1.233 is the adjusting coefficient for the Chinese. ${ }^{17}$

A single, first-morning-void urine sample was collected for the measurement of urinary albumin and creatinine. Urinary albumin concentration was measured by an immunoturbidimetric method (Beijing Atom High-Tech, Beijing, China) and urinary creatinine concentration was determined by Jaffe's kinetic method on an autoanalyzer (Hitachi 7600-020, Tokyo, Japan). Urinary ACR was calculated as milligrams of urinary albumin excretion per gram of urinary creatinine. Those with the highest quartile of urinary ACR were classified as having lowgrade albuminuria $(\mathrm{ACR}>6.10 \mathrm{mg} / \mathrm{g}$ in males and $>8.76 \mathrm{mg} / \mathrm{g}$ in females).

\section{Statistical analysis}

All statistical analyses were conducted using SAS V.9.2 (SAS Institute Inc, Cary, North Carolina, USA). Continuous variables were presented as means \pm SDs or medians (IQRs) for skewed variables. Categorical variables were expressed as numbers (proportions).

Participants were categorised into five groups based on their HbA1c levels: $\leq 37 \mathrm{mmol} / \mathrm{mol}$ (5.5\%), 38$42 \mathrm{mmol} / \mathrm{mol}$ (5.6-6.0\%), $43-48 \mathrm{mmol} / \mathrm{mol}(6.1-6.5 \%)$, $49-53 \mathrm{mmol} / \mathrm{mol} \quad(6.6-7.0 \%)$, and $>53 \mathrm{mmol} / \mathrm{mol}$ $(7.0 \%)$. Differences among the five groups were analysed by one-way analysis of variance (ANOVA) for continuous 
variables and $\chi^{2}$ test for categorical variables. The $p$ values for trend were tested using linear regression and the Cochran-Mantel-Haenszel (CMH) method for continuous and categorical variables, respectively. Associations of urinary ACR levels with each 1-SD increase in glycaemic indicators (ie, FPG, $2 \mathrm{~h}$ PG and HbA1c) were examined using linear regression models at different levels of adjustment, with urinary ACR logtransformed before analyses.

Logistic regression models were used to evaluate the association between HbAlc levels and low-grade albuminuria. The risk of low-grade albuminuria in relation to each $5.5 \mathrm{mmol} / \mathrm{mol}(0.5 \%)$ increment of HbAlc was further explored in subgroups stratified by age $(\geq 65 /$ $<65$ years), sex (male/female), physical activity (low/ moderate/high), current smoker (yes/no), current drinker (yes/no), obesity (yes/no), diabetes (yes/no), duration of diabetes $(\geq 5 /<5$ years), use of antidiabetic drugs (yes/no), and use of ACE inhibitor (ACEI)/angiotensin receptor blocker (ARB) drugs (yes/no) with adjustment for potential confounding factors.

Significant tests were two tailed and a $\mathrm{p}$ value $<0.05$ was considered statistically significant.

\section{RESULTS}

\section{Characteristics of participants}

Table 1 shows demographic and cardiometabolic characteristics of the study population by HbAlc categories. In groups with higher HbA1c levels, participants were older, less likely to be physically active, and had higher levels of BMI, SBP, DBP, TG, LDL-c, FPG, 2 h PG and HOMA-IR as well as increased prevalences of obesity, hypertension and diabetes, but lower levels of HDL-c and education (all $\mathrm{p}_{\text {for trend }}<0.0001$ ). In addition, $5.4 \%$ of study participants were taking ACEI/ARB medications and $6.2 \%$ of participants were using antidiabetic drugs. Generally, the proportions increased with elevated HbAlc levels $\left(p_{\text {for trend }}<0.0001\right.$ ). The mean duration of diabetes in previously diagnosed diabetes was 4.9 years.

Urinary ACR increased significantly with increasing HbA1c levels $\left(p_{\text {for trend }}<0.0001\right.$; table 1 ). Likewise, a significant increase in the prevalence of low-grade albuminuria was observed according to different HbAlc levels $(21.3 \%, 23.9 \%, 29.2 \%, 35.6 \%$ and $47.5 \%$ in HbA1c categories of $\leq 37 \mathrm{mmol} / \mathrm{mol}(5.5 \%), \quad 38-42 \mathrm{mmol} / \mathrm{mol}$ (5.6-6.0\%), $43-48 \mathrm{mmol} / \mathrm{mol}(6.1-6.5 \%), 49-53 \mathrm{mmol} /$ $\mathrm{mol}(6.6-7.0 \%)$ and $>53 \mathrm{mmol} / \mathrm{mol}(7.0 \%)$, respectively; $\mathrm{p}_{\text {for trend }}<0.0001$, figure 1$)$.

\section{Associations between urinary ACR and glycaemic indicators}

The univariate analysis revealed that urinary ACR was significantly associated with HbAlc, FPG and $2 \mathrm{~h}$ PG. The associations remained significant after adjustment for confounding factors such as age, sex, smoking and drinking status, physical activity, BMI, SBP, lipids, medications and eGFR (all $\mathrm{p}<0.0001$ ). Further adjustment for HbAlc levels reduced the associations of ACR with FPG and $2 \mathrm{~h}$ PG to null. HbAlc was still significantly associated with ACR after further adjustment for FPG and 2 h PG ( $<<0.0001$, table 2$)$.

\section{Associations between low-grade albuminuria and HbA1c} Using participants with $\mathrm{HbA} 1 \mathrm{c} \leq 37 \mathrm{mmol} / \mathrm{mol}(5.5 \%)$ as the reference group, a dose-response relationship was found between HbAlc levels and risks of low-grade albuminuria (table 3). Although the magnitude of association was decreased after adjustment for confounding factors, it remained significant, especially for groups with higher HbAlc levels. Further adjustment for FPG and 2 h PG caused little change and the dose-response relationship still remained (ORs were 1.00, 1.05, 1.25, 1.40 and 2.21 for $\mathrm{HbAlc}$ categories of $\leq 37 \mathrm{mmol} / \mathrm{mol}(5.5 \%)$, 38 $42 \mathrm{mmol} / \mathrm{mol}$ (5.6-6.0\%), $43-48 \mathrm{mmol} / \mathrm{mol}(6.1-6.5 \%)$, $49-53 \mathrm{mmol} / \mathrm{mol}(6.6-7.0 \%)$ and $>53 \mathrm{mmol} / \mathrm{mol}(7.0 \%)$, respectively; $\mathrm{p}_{\text {for trend }}<0.0001$, table 3 ). The association between low-grade albuminuria and HbA1c was fairly consistent among subgroups ( $p$ values for interaction $>0.05$ ), except for the subgroup of obesity ( $p$ value for interaction=0.033; figure 2). Moreover, the receiver operating characteristic curve (ROC) analysis revealed that the area under the curve was $0.58(0.56-0.59)$ and the optimal cut-off value of HbAlc for low-grade albuminuria was $39 \mathrm{mmol} / \mathrm{mol}(5.7 \%)$ with the largest Youden Index.

\section{DISCUSSION}

In this study, we found a significant association between HbA1c levels and risks of low-grade albuminuria, after controlling for confounding factors including FPG and $2 \mathrm{~h}$ PG. In contrast, no significant associations were detected between FPG, $2 \mathrm{~h}$ PG and urinary ACR levels after adjustment for HbAlc.

Previous studies have already reported the associations between FPG, 2 h PG, HbAlc and low-grade albuminuria. Sung et $a l^{18}$ showed that FPG was closely related to low-grade albuminuria in the overall study population, but for persons without diabetes and those without hypertension, the association no longer existed. Nevertheless, this study might be the first to evaluate and compare associations of all three glycaemic markers with low-grade albuminuria in a general Chinese population with adjustment for conventional cardiovascular risk factors.

Previous studies have demonstrated a positive association between HbA1c and microalbuminuria. ${ }^{19}{ }^{20}$ In persons with diabetes, Krolewski et $a l^{19}$ reported an HbAlc threshold of $87 \mathrm{mmol} / \mathrm{mol}(10.1 \%)$, above which the risk of microalbuminuria rose steeply. Additionally, among patients with type 2 diabetes, the risk of microalbuminuria was also closely related to HbAlc levels in Southern India. ${ }^{20}$ However, associations between microalbuminuria and HbA1c were studied mainly in patients with diabetes, as well as in studies with small sample 
Table 1 General characteristics of study participants by HbA1c levels

HbA1c levels

\begin{tabular}{|c|c|c|c|c|c|c|c|}
\hline & Total & $\leq 37 \mathrm{mmol} / \mathrm{mol}(5.5 \%)$ & $\begin{array}{l}38-42 \mathrm{mmol} / \mathrm{mol} \\
(5.6-6.0 \%)\end{array}$ & $\begin{array}{l}43-48 \mathrm{mmol} / \mathrm{mol} \\
(6.1-6.5 \%)\end{array}$ & $\begin{array}{l}49-53 \mathrm{mmol} / \mathrm{mol} \\
(6.6-7.0 \%)\end{array}$ & $>53 \mathrm{mmol} / \mathrm{mol}(7.0 \%)$ & P For trend \\
\hline Participants (n (\%)) & 9188 & 3949 (43.0) & $3513(38.2)$ & $932(10.2)$ & 295 (3.2) & $499(5.4)$ & \\
\hline Urinary ACR (mg/g) & $4.55(2.67-7.81)$ & $4.21(2.51-6.99)$ & $4.60(2.71-7.74)$ & $4.93(2.91-8.78)$ & $5.62(3.10-10.66)$ & $6.89(3.66-13.08)$ & $<0.0001$ \\
\hline Age (years) & $58.2 \pm 9.6$ & $56.5 \pm 9.8$ & $58.9 \pm 9.2$ & $60.8 \pm 9.1$ & $61.0 \pm 9.1$ & $60.6 \pm 9.2$ & $<0.0001$ \\
\hline Male $(\mathrm{n}(\%))$ & 3525 (38.4) & $1596(40.4)$ & $1223(34.8)$ & $348(37.3)$ & $107(36.3)$ & $251(50.3)$ & 0.13 \\
\hline Physical activity (n (\%)) & & & & & & & $<0.0001$ \\
\hline Low & $7624(83.0)$ & $3184(80.6)$ & $2953(84.0)$ & $803(86.1)$ & $262(88.8)$ & $422(84.6)$ & \\
\hline Moderate & $507(5.5)$ & $232(5.9)$ & $203(5.8)$ & $36(3.9)$ & $16(5.4)$ & $20(4.0)$ & \\
\hline High & $1057(11.5)$ & $533(13.5)$ & $357(10.2)$ & $93(10.0)$ & $17(5.8)$ & $57(11.4)$ & \\
\hline Current smoker (n (\%)) & $1885(21.2)$ & $1845(22.2)$ & $664(19.5)$ & $168(18.7)$ & $52(18.3)$ & $156(32.0)$ & 0.047 \\
\hline Current drinker (n (\%)) & $918(10.3)$ & $437(11.5)$ & $325(9.5)$ & $85(9.4)$ & $20(7.0)$ & $51(10.5)$ & 0.028 \\
\hline High school education or above (n (\%)) & $1976(21.5)$ & $979(24.8)$ & $675(19.2)$ & $164(17.6)$ & 54 (18.3) & $104(20.8)$ & $<0.0001$ \\
\hline BMI $\left(\mathrm{kg} / \mathrm{m}^{2}\right)$ & $25.0 \pm 3.2$ & $24.4 \pm 3.0$ & $25.2 \pm 3.2$ & $26.0 \pm 3.3$ & $26.7 \pm 3.4$ & $26.2 \pm 3.4$ & $<0.0001$ \\
\hline $\mathrm{SBP}(\mathrm{mm} \mathrm{Hg})$ & $140.2 \pm 19.6$ & $136.9 \pm 19.2$ & $140.8 \pm 19.3$ & $145.5 \pm 19.4$ & $147.3 \pm 18.6$ & $148.2 \pm 20.8$ & $<0.0001$ \\
\hline $\mathrm{DBP}(\mathrm{mm} \mathrm{Hg})$ & $82.6 \pm 10.2$ & $82.1 \pm 10.2$ & $82.6 \pm 10.1$ & $83.6 \pm 10.2$ & $83.2 \pm 10.5$ & $83.7 \pm 10.3$ & $<0.0001$ \\
\hline $\mathrm{TG}(\mathrm{mmol} / \mathrm{L})$ & $1.37(0.97-1.93)$ & $1.26(0.91-1.81)$ & $1.37(0.97-1.90)$ & $1.57(1.13-2.17)$ & $1.57(1.20-2.17)$ & $1.75(1.23-2.62)$ & $<0.0001$ \\
\hline HDL-c (mmol/L) & $1.33 \pm 0.32$ & $1.34 \pm 0.32$ & $1.34 \pm 0.32$ & $1.29 \pm 0.30$ & $1.27 \pm 0.29$ & $1.24 \pm 0.29$ & $<0.0001$ \\
\hline LDL-c (mmol/L) & $3.19 \pm 0.86$ & $3.03 \pm 0.80$ & $3.27 \pm 0.86$ & $3.37 \pm 0.90$ & $3.35 \pm 0.91$ & $3.40 \pm 0.97$ & $<0.0001$ \\
\hline $\mathrm{FPG}(\mathrm{mmol} / \mathrm{L})$ & $5.2(4.8-5.7)$ & $4.94(4.62-5.27)$ & $5.17(4.83-5.58)$ & $5.78(5.23-6.45)$ & $6.72(6.14-7.50)$ & $8.76(7.52-10.88)$ & $<0.0001$ \\
\hline $2 \mathrm{~h} \mathrm{PG}(\mathrm{mmol} / \mathrm{L})$ & $6.9(5.6-9.0)$ & $6.25(5.25-7.43)$ & $6.94(5.73-8.45)$ & $9.23(6.90-12.40)$ & $13.68(11.13-16.26)$ & $18.63(15.56-22.52)$ & $<0.0001$ \\
\hline eGFR $\left(\mathrm{mL} / \mathrm{min} / 1.73 \mathrm{~m}^{2}\right)$ & $108.2 \pm 20.2$ & $108.6 \pm 19.5$ & $106.7 \pm 19.3$ & $106.0 \pm 20.6$ & $110.0 \pm 19.8$ & $119.0 \pm 26.5$ & $<0.0001$ \\
\hline HOMA-IR & $1.39(1.05-2.43)$ & $1.39(0.94-2.01)$ & $1.57(1.07-2.35)$ & $2.07(1.27-3.12)$ & $2.70(1.68-4.21)$ & $3.43(2.07-5.33)$ & $<0.0001$ \\
\hline Hypertension (n (\%)) & $5375(58.6)$ & $2036(51.6)$ & $2086(59.6)$ & $649(69.8)$ & $225(76.5)$ & $379(76.0)$ & $<0.0001$ \\
\hline Diabetes (n (\%)) & $1547(16.8)$ & $148(3.8)$ & $299(8.5)$ & $363(39.0)$ & $245(83.1)$ & $492(98.6)$ & $<0.0001$ \\
\hline Newly diagnosed & $867(9.4)$ & $114(2.9)$ & $218(6.2)$ & $219(23.5)$ & $129(43.7)$ & $187(37.5)$ & \\
\hline Previously diagnosed & $680(7.4)$ & $34(0.9)$ & $81(2.3)$ & $144(15.5)$ & $116(39.3)$ & $305(61.1)$ & \\
\hline Duration of diabetes (years) ${ }^{*}$ & $4.9(2.1-8.8)$ & $4.3(1.2-8.5)$ & $2.8(1.1-6.6)$ & $4.5(2.0-7.1)$ & $3.8(2.0-7.4)$ & $6.0(3.0-9.9)$ & \\
\hline Obesity (n (\%)) & $1579(17.2)$ & $484(12.3)$ & $636(18.1)$ & $236(25.3)$ & 95 (32.3) & $128(25.7)$ & $<0.0001$ \\
\hline Use of ACEI/ARB drugs ( $n(\%))$ & $494(5.4)$ & $165(4.2)$ & $182(5.2)$ & $76(8.2)$ & $30(10.2)$ & $41(8.2)$ & $<0.0001$ \\
\hline Use of antidiabetic drugs ( $\mathrm{n}(\%)$ ) & $573(6.2)$ & $26(0.7)$ & $63(1.8)$ & $122(13.1)$ & $102(34.6)$ & $260(52.1)$ & $<0.0001$ \\
\hline
\end{tabular}

Data were means \pm SDs or medians $(I Q R)$ for continuous variables, and numbers (percentages) for categorical variables. Data were missing for current smoker $(n=302)$, current drinker ( $n=286)$, $\operatorname{SBP}(n=19)$, DBP $(n=18)$ and HDL-c $(n=1)$

$\mathrm{p}$ Values for trend were calculated by linear regression for continuous variables and $\chi^{2}$ test for categorical variables.

*Data were calculated in participants with previously diagnosed diabetes.

$2 \mathrm{~h}$ PG, $2 \mathrm{~h}$ postload plasma glucose; ACEI, ACE inhibitor; ACR, albumin-to-creatinine ratio; ARB, angiotensin receptor blocker; BMI, body mass index; DBP, diastolic blood pressure; eGFR,

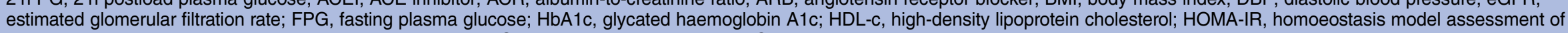
insulin resistance; LDL-c, low-density lipoprotein cholesterol; SBP, systolic blood pressure; TG, triglyceride. 
Figure 1 Prevalence of low-grade albuminuria according to different glycated haemoglobin A1c $(\mathrm{HbA1c})$ levels. $\mathrm{p}$ Values were calculated using the $\chi^{2}$ test.

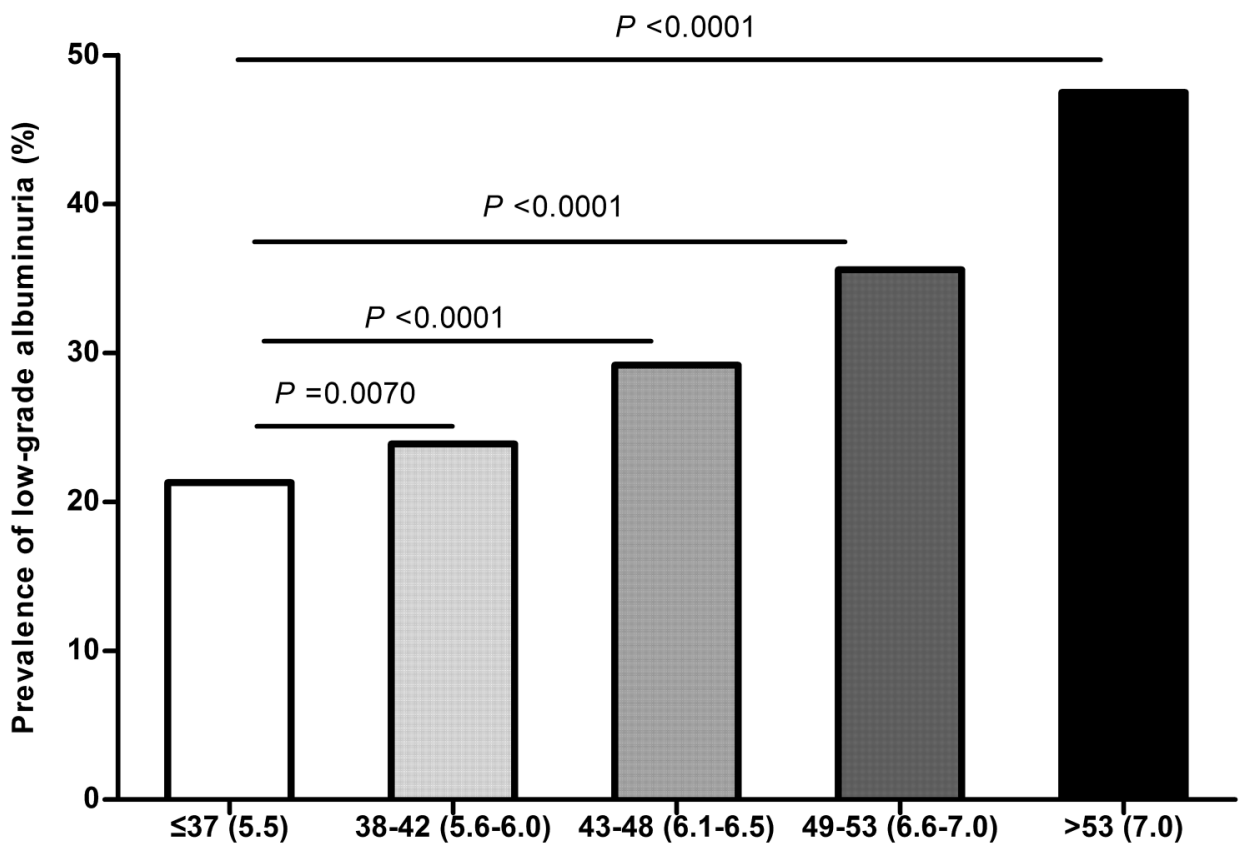

HbA1c levels [mmol/mol (\%)] sizes. Therefore, the generalisability of the results was limited. In this context, this study was designed to use a general community-based population to include both individuals with diabetes and individuals without diabetes. We found that participants with higher $\mathrm{HbAlc}$ levels were more likely to have combined microalbuminuria and macroalbuminuria in Chinese adults (data not shown), which was in agreement with previous studies. Moreover, we found a positive association between glycaemic markers and low-grade albuminuria, which is an earlier predictive factor of cardiovascular diseases. $^{6-8}$ 21-23 A retrospective analysis revealed that any degrees of urinary albuminuria were risk factors of cardiovascular diseases. ${ }^{2}$ The Framingham Heart Study showed that there were sex-specific thresholds of urinary ACR (3.9 mg/g for males and $7.5 \mathrm{mg} / \mathrm{g}$ for females) for an increased incidence of cardiovascular events and mortality. ${ }^{6}$ In a community-based sample of elderly individuals in Europe, low-grade albuminuria was a marker for subclinical cardiovascular damage, which predisposed heart failure in the future. ${ }^{7}$ Moreover, the Strong Heart Study conducted in American Indians also reported that albuminuria within the 'normal' range $(<30 \mathrm{mg} / \mathrm{g})$ predicted cardiovascular diseases. ${ }^{23}$

Associations between glycaemic markers and cardiovascular disease predictors or cardiovascular diseases were extensively investigated in the literature. ${ }^{24-28}$ The Atherosclerosis Risk in Communities (ARIC) study found that elevated HbAlc, but not FPG, was associated with the risk of cardiovascular events in individuals without diabetes. ${ }^{25}$ The Strong Heart Study reported that increases in FPG and HbAlc were associated with increased risks of cardiovascular diseases. ${ }^{26}$ Moreover, Huang $e t a l^{28}$ assessed the associations of HbAlc, FPG and $2 \mathrm{~h}$ PG with carotid intima-media thickness (CIMT) in respondents with normal glucose tolerance. The authors found that higher HbAlc levels were significantly associated with elevated CIMT independent of

Table 2 Associations of urinary ACR with each 1-SD increase in FPG, 2 h PG and HbA1c

\begin{tabular}{|c|c|c|c|c|c|c|}
\hline \multirow[b]{2}{*}{ Variables } & \multicolumn{2}{|l|}{ Model 1} & \multicolumn{2}{|l|}{ Model 2} & \multicolumn{2}{|l|}{ Model 3} \\
\hline & $\beta \pm \mathbf{S E}$ & p Value & $\beta \pm \mathrm{SE}$ & p Value & $\beta \pm \mathbf{S E}$ & p Value \\
\hline $\mathrm{FPG}^{*}$ & $0.090 \pm 0.008$ & $<0.0001$ & $0.049 \pm 0.009$ & $<0.0001$ & $-0.003 \pm 0.014$ & 0.84 \\
\hline $2 \mathrm{~h} \mathrm{PG}^{*}$ & $0.106 \pm 0.008$ & $<0.0001$ & $0.040 \pm 0.010$ & $<0.0001$ & $-0.008 \pm 0.013$ & 0.54 \\
\hline $\mathrm{HbA1c}{ }^{* *}$ & $0.110 \pm 0.008$ & $<0.0001$ & $0.067 \pm 0.009$ & $<0.0001$ & $0.072 \pm 0.014$ & $<0.0001$ \\
\hline
\end{tabular}

Model 1: Unadjusted.

Model 2: Adjusted for age, sex, smoking and drinking status, physical activity, BMI, TG, HDL-c, LDL-c, SBP, use of ACEl/ARB drugs, use of antidiabetic drugs and eGFR.

Model 3: *Further adjusted for $\mathrm{HbA} 1 \mathrm{c}$ based on model 2; **further adjusted for FPG and $2 \mathrm{~h}$ PG based on model 2.

$\beta$, regression coefficient; $2 \mathrm{~h} \mathrm{PG}, 2 \mathrm{~h}$ postload glucose; ACEI, ACE inhibitor; ACR, albumin-to-creatinine ratio; ARB, angiotensin receptor blocker; BMI, body mass index; eGFR, estimated glomerular filtration rate; FPG, fasting plasma glucose; HbA1c, glycated haemoglobin A1c; HDL-c, high-density lipoprotein cholesterol; LDL-c, low-density lipoprotein cholesterol; SBP, systolic blood pressure; TG, triglyceride. 
Table 3 Associations of risks of low-grade albuminuria with $\mathrm{HbA} 1 \mathrm{c}$ levels

\begin{tabular}{|c|c|c|c|c|c|c|}
\hline \multirow[b]{2}{*}{ Model } & \multicolumn{5}{|l|}{ HbA1c levels } & \multirow[b]{2}{*}{ PFor trend } \\
\hline & $\begin{array}{l}\leq 37 \mathrm{mmol} / \mathrm{mol} \\
(5.5 \%)\end{array}$ & $\begin{array}{l}38-42 \mathrm{mmol} / \mathrm{mol} \\
(5.6-6.0 \%)\end{array}$ & $\begin{array}{l}\text { 43-48 } \mathrm{mmol} / \mathrm{mol} \\
(6.1-6.5 \%)\end{array}$ & $\begin{array}{l}49-53 \mathrm{mmol} / \mathrm{mol} \\
(6.6-7.0 \%)\end{array}$ & $\begin{array}{l}>53 \mathrm{mmol} / \mathrm{mol} \\
(7.0 \%)\end{array}$ & \\
\hline Model 1 & 1.00 & $1.16(1.04-1.30)$ & $1.52(1.30-1.79)$ & $2.04(1.59-2.62)$ & $3.34(2.76-4.05)$ & $<0.0001$ \\
\hline Model 2 & 1.00 & $1.05(0.94-1.18)$ & $1.24(1.05-1.48)$ & $1.40(1.06-1.84)$ & $2.25(1.77-2.85)$ & $<0.0001$ \\
\hline Model 3 & 1.00 & $1.05(0.94-1.18)$ & $1.25(1.04-1.50)$ & $1.40(1.04-1.90)$ & $2.21(1.61-3.03)$ & $<0.0001$ \\
\hline \multicolumn{7}{|c|}{$\begin{array}{l}\text { Data were ORs (95\% Cls). } \\
\text { Model 1: Unadjusted. } \\
\text { Model 2: Adjusted for age, sex, smoking and drinking status, physical activity, BMI, TG, HDL-c, LDL-c, SBP, use of ACEl/ARB drugs, use of } \\
\text { antidiabetic drugs and eGFR. } \\
\text { Model 3: Further adjusted for FPG and } 2 \mathrm{~h} \text { PG based on model } 2 \text {. } \\
2 \mathrm{~h} \text { PG, } 2 \mathrm{~h} \text { postload glucose; ACEI, ACE inhibitor; ARB, angiotensin receptor blocker; BMl, body mass index; eGFR, estimated glomerular } \\
\text { filtration rate; FPG, fasting plasma glucose; HbA1c, glycated haemoglobin A1c; HDL-c, high-density lipoprotein cholesterol; LDL-c, low-density } \\
\text { lipoprotein cholesterol; SBP, systolic blood pressure; TG, triglyceride. }\end{array}$} \\
\hline
\end{tabular}

conventional cardiovascular risk factors, whereas FPG and $2 \mathrm{~h}$ PG were not associated with CIMT. Similar results were found in this study, with an independent association between HbA1c and low-grade albuminuria, and a lack of independent correlation of urinary ACR with FPG and $2 \mathrm{~h}$ PG.

Additionally, since the duration of diabetes is a very important confounder for the association between $\mathrm{HbAlc}$

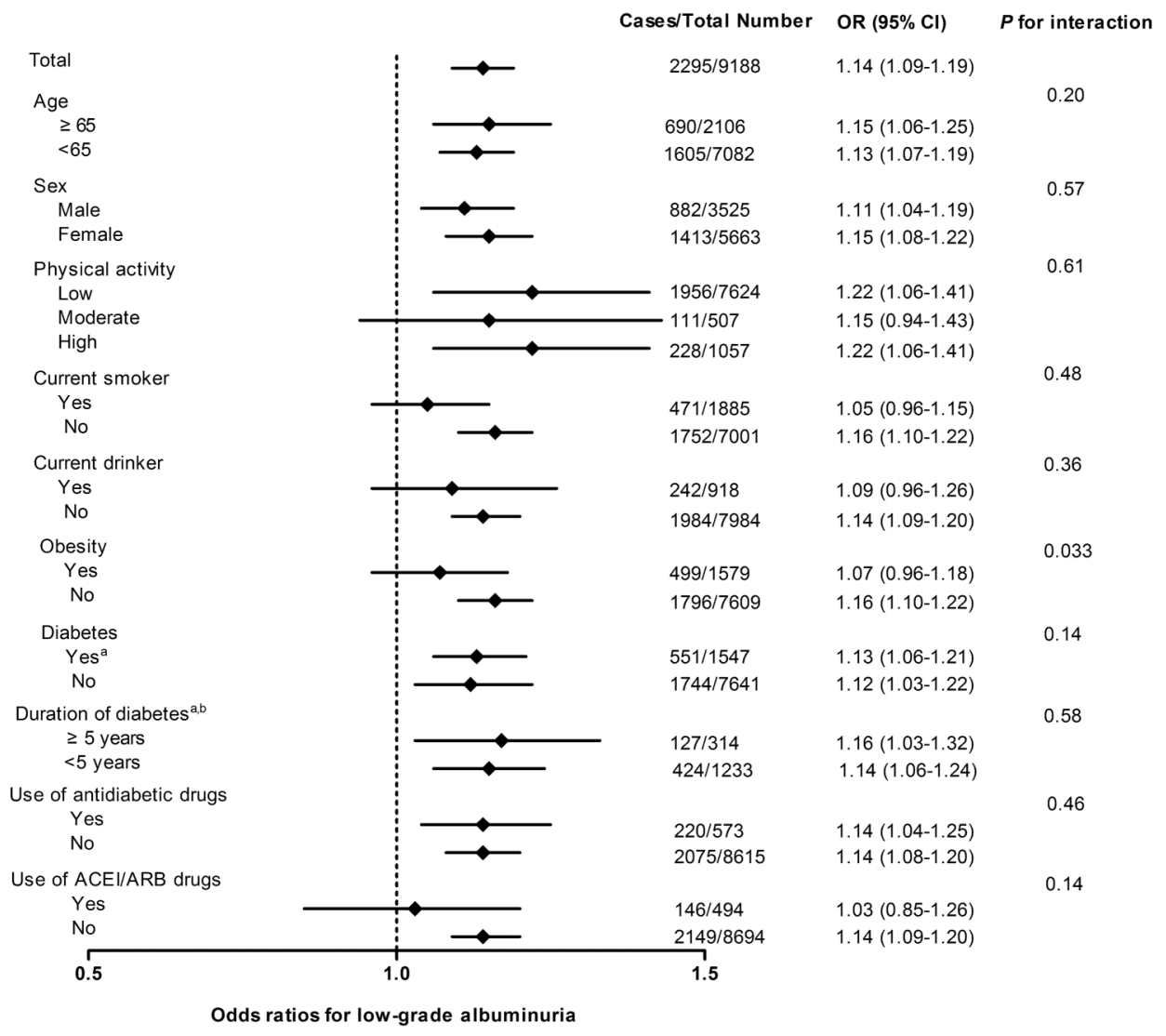

Figure 2 Adjusted ORs of low-grade albuminuria associated with each $5.5 \mathrm{mmol} / \mathrm{mol}(0.5 \%)$ increase in $\mathrm{HbA} 1 \mathrm{c}$ in subgroups. All models were adjusted for potential confounding factors including sex (except for sex strata), age, smoking status (except for current smoker strata), drinking status (except for current drinker strata), physical activity (except for physical activity strata), BMI, TG, HDL-c, LDL-C, SBP, use of ACEl/ARB drugs (except for use of ACEl/ARB drugs strata), use of antidiabetic drugs (except for use of antidiabetic drugs strata), eGFR, FPG and $2 \mathrm{~h} \mathrm{PG}$. ${ }^{a}$ Data were analysed with further adjustment for duration of diabetes. ${ }^{b}$ Data were analysed in individuals with diabetes, including those newly diagnosed and those who have been previously diagnosed. (2 h PG, 2 h postload glucose; ACEI, ACE inhibitor; ARB, angiotensin receptor blocker; BMI, body mass index; FPG, fasting plasma glucose; eGFR, estimated glomerular filtration rate; HbA1c, glycated haemoglobin A1c; HDL-c, high-density lipoprotein cholesterol; LDL-c, low-density lipoprotein cholesterol; SBP, systolic blood pressure; TG, triglyceride). 
and low-grade albuminuria, it was taken into consideration by adjustment when estimating the OR as well as by stratification on this variable (duration of diabetes $\geq 5$ and $<5$ years) in individuals with diabetes. The association between HbAlc levels and risks of low-grade albuminuria in diabetes remained significant after the adjustment as well as in different strata of diabetes duration. Similarly, to consider the important role of antidiabetic and ACEI/ ARB drugs in the association, subgroup analyses in participants without antidiabetic or ACEI/ARB medications were also conducted with significant findings. Moreover, the association of HbAlc levels with low-grade albuminuria among other subgroups was largely consistent, except that it differed between participants with and without obesity. The potential modifying effect of obesity status might be due to its impact on the development of albuminuria as well as on glucose homoeostasis. ${ }^{29} 30$

HbA1c values reflect average blood glucose levels including postprandial plasma glucose spikes over the past 2-3 months, and have low variability, particularly in individuals without diabetes. ${ }^{31}{ }^{32}$ These characteristics may contribute to the superiority of HbAlc over FPG, which primarily reflects hepatic glucose output at the time of sampling, in predicting long-term macrovascular diseases as well as low-grade albuminuria and other early cardiovascular disease predictors. In addition, the larger variability of $2 \mathrm{~h}$ PG relative to FPG and HbAlc demonstrated by Selvin $e t a l^{31}$ may result in a lack of significant association between $2 \mathrm{~h}$ PG and urinary ACR, although $2 \mathrm{~h}$ PG was reported to be associated with cardiovascular diseases in patients with diabetes. ${ }^{33}$

The potential pathophysiological mechanism linking HbA1c concentrations and low-grade albuminuria might involve several different pathways. Among individuals with $\mathrm{HbAlc}$ levels $<48 \mathrm{mmol} / \mathrm{mol}(6.5 \%)$, insulin resistance could result in changes in the amount and/or the effects of nitric oxide and other chemical mediators by causing endothelial dysfunction. ${ }^{34-36}$ The dysfunction of the glomerular capillary wall might lead to increased leakage of albuminuria at the glomerulus. ${ }^{37}$ For individuals with high HbA1c levels, elevated albuminuria was most likely caused by chronic hyperglycaemia, which resulted in loss of charge of selectivity and glomerular hyperperfusion and hyperfiltration accompanied by glycation of basement membrane proteins. ${ }^{38-40}$

Several limitations of our study should be mentioned. First, owing to the cross-sectional characteristic of this study, we draw no conclusion about cause and effect between HbA1c concentrations and low-grade albuminuria. Second, urinary albumin excretion was examined at a single time. Previous studies have shown that a $24 \mathrm{~h}$ urine sample or three samples from three consecutive days would yield results of more stable urine albumin excretion. ${ }^{41}$ Nevertheless, it was reported that use of spot urine could be a reliable alternative to $24 \mathrm{~h}$ urinary albumin excretion due to its good agreement with $24 \mathrm{~h}$ urinary albumin excretion, as well as the convenience of large epidemiological studies. ${ }^{42} 43$
In conclusion, our study demonstrated that elevated $\mathrm{HbAlc}$ concentrations were associated with increased risks of low-grade albuminuria and might have superiority over FPG and $2 \mathrm{~h}$ PG in the middle-aged and elderly Chinese. Prospective studies are warranted to determine the role of HbA1c in the development of low-grade albuminuria and compare the association to that of FPG and 2 h PG with low-grade albuminuria. Whether interventional measures to decrease HbAlc levels were associated with reduced risks of low-grade albuminuria is also a matter of interest.

Acknowledgements The authors thank all the participants for their contribution and participation.

Contributors $\mathrm{XH}, \mathrm{YZ}, \mathrm{YX}$ and GN contributed to the conception and design of this study. XH, YZ, BX, WS, LL and JS were involved in the acquisition of data. $\mathrm{XH}$ and $\mathrm{YZ}$ conducted the statistical analysis and interpretation of data, and drafted the manuscript. MX, JL, YB, WW, YX and GN contributed to the revision of the manuscript for important intellectual content. All authors read and approved the final manuscript.

Funding This work is supported by grants from the Key Laboratory for Endocrine and Metabolic Diseases of Ministry of Health (1994DP131044), the National Clinical Research Center for Metabolic Diseases of Ministry of Health (2013BAI09B13), the National Key New Drug Creation and Manufacturing Program of Ministry of Science and Technology (2012ZX09303006-001), the National High Technology Research and Development Program of China (863 Program, 2012AA02A509), and the National Natural Science Foundation of China $(81100564,81321001,81030011,81130016,81222008$, and 81270877).

Competing interests None declared.

Patient consent Obtained.

Ethics approval The study protocol was approved by the Institutional Review Board of the Rui-Jin Hospital and was in accordance with the principle of Helsinki Declaration II.

Provenance and peer review Not commissioned; externally peer reviewed.

Data sharing statement The data set for this study is available on request from the corresponding author.

Open Access This is an Open Access article distributed in accordance with the Creative Commons Attribution Non Commercial (CC BY-NC 4.0) license, which permits others to distribute, remix, adapt, build upon this work noncommercially, and license their derivative works on different terms, provided the original work is properly cited and the use is non-commercial. See: http:// creativecommons.org/licenses/by-nc/4.0/

\section{REFERENCES}

1. Gerstein HC, Mann JF, Pogue J, et al. Prevalence and determinants of microalbuminuria in high-risk diabetic and nondiabetic patients in the Heart Outcomes Prevention Evaluation Study. The HOPE Study Investigators. Diabetes Care 2000;23(Suppl 2):B35-9.

2. Gerstein HC, Mann JF, Yi Q, et al. Albuminuria and risk of cardiovascular events, death, and heart failure in diabetic and nondiabetic individuals. JAMA 2001;286:421-6.

3. de Zeeuw D, Parving HH, Henning RH. Microalbuminuria as an early marker for cardiovascular disease. J Am Soc Nephrol 2006;17:2100-5.

4. Valmadrid CT, Klein R, Moss SE, et al. The risk of cardiovascular disease mortality associated with microalbuminuria and gross proteinuria in persons with older-onset diabetes mellitus. Arch Intern Med 2000;160:1093-100.

5. Stehouwer CD, Gall MA, Twisk JW, et al. Increased urinary albumin excretion, endothelial dysfunction, and chronic low-grade inflammation in type 2 diabetes: progressive, interrelated, and independently associated with risk of death. Diabetes 2002;51:1157-65.

6. Arnlov J, Evans JC, Meigs JB, et al. Low-grade albuminuria and incidence of cardiovascular disease events in nonhypertensive and 
nondiabetic individuals: the Framingham Heart Study. Circulation 2005;112:969-75.

7. Ingelsson E, Sundstrom J, Lind L, et al. Low-grade albuminuria and the incidence of heart failure in a community-based cohort of elderly men. Eur Heart J 2007;28:1739-45.

8. Klausen K, Borch-Johnsen K, Feldt-Rasmussen B, et al. Very low levels of microalbuminuria are associated with increased risk of coronary heart disease and death independently of renal function, hypertension, and diabetes. Circulation 2004;110:32-5.

9. Mangiapane H. Cardiovascular disease and diabetes. Adv Exp Med Biol 2012;771:219-28.

10. Selvin E, Marinopoulos S, Berkenblit G, et al. Meta-analysis: glycosylated hemoglobin and cardiovascular disease in diabetes mellitus. Ann Intern Med 2004;141:421-31.

11. Gerstein HC, Miller ME, Byington RP, et al. Effects of intensive glucose lowering in type 2 diabetes. $N$ Engl $\mathrm{J}$ Med 2008;358:2545-59.

12. Holman RR, Paul SK, Bethel MA, et al. 10-year follow-up of intensive glucose control in type 2 diabetes. $N$ Engl J Med 2008;359:1577-89.

13. Li M, Xu Y, Xu M, et al. Association between nonalcoholic fatty liver disease (NAFLD) and osteoporotic fracture in middle-aged and elderly Chinese. J Clin Endocrinol Metab 2012;97:2033-8.

14. Huang $\mathrm{Y}, \mathrm{Bi} \mathrm{Y}, \mathrm{Xu} \mathrm{M}$, et al. Nonalcoholic fatty liver disease is associated with atherosclerosis in middle-aged and elderly Chinese. Arterioscler Thromb Vasc Biol 2012;32:2321-6.

15. The IPAQ group. International physical activity questionnaire. 2014 . http://www.ipaq.ki.se/scoring.pdf (accessed 10 Dec 2014).

16. World Health Organization. Obesity: preventing and managing the global epidemic. 1997. http://www.who.int/nutrition/publications/ obesity executive summary.pdf (accessed 10 Dec 2014).

17. Ma YC, Zuo L, Chen JH, et al. Modified glomerular filtration rate estimating equation for Chinese patients with chronic kidney disease. J Am Soc Nephrol 2006;17:2937-44.

18. Sung KC, Kim BJ, Ryu S. An association of a variety of cardiovascular risk factors with low grade albuminuria in Korean men. Atherosclerosis 2008;196:320-6.

19. Krolewski AS, Laffel LM, Krolewski M, et al. Glycosylated hemoglobin and the risk of microalbuminuria in patients with insulindependent diabetes mellitus. N Engl J Med 1995;332:1251-5.

20. Varghese A, Deepa R, Rema M, et al. Prevalence of microalbuminuria in type 2 diabetes mellitus at a diabetes centre in southern India. Postgrad Med J 2001;77:399-402.

21. Schmieder RE, Schrader J, Zidek W, et al. Low-grade albuminuria and cardiovascular risk: what is the evidence? Clin Res Cardiol 2007;96:247-57.

22. Wang TJ, Evans JC, Meigs JB, et al. Low-grade albuminuria and the risks of hypertension and blood pressure progression. Circulation 2005;111:1370-6.

23. $\mathrm{Xu} \mathrm{J}$, Knowler WC, Devereux RB, et al. Albuminuria within the "normal" range and risk of cardiovascular disease and death in American Indians: the Strong Heart Study. Am J Kidney Dis 2007:49:208-16.

24. Meigs JB, Nathan DM, D'Agostino RB, et al. Fasting and postchallenge Glycemia and cardiovascular disease risk: the Framingham Offspring Study. Diabetes Care 2002;25:1845-50.

25. Selvin E, Steffes MW, Zhu H, et al. Glycated hemoglobin, diabetes, and cardiovascular risk in nondiabetic adults. $N$ Engl $\mathrm{J} \mathrm{Med}$ 2010;362:800-11.
26. Wang $\mathrm{H}$, Shara NM, Lee ET, et al. Hemoglobin A1c, fasting glucose, and cardiovascular risk in a population with high prevalence of diabetes: the Strong Heart Study. Diabetes Care 2011;34:1952-8.

27. Cederberg H, Saukkonen T, Laakso M, et al. Postchallenge glucose, $\mathrm{A} 1 \mathrm{C}$, and fasting glucose as predictors of type 2 diabetes and cardiovascular disease: a 10-year prospective cohort study. Diabetes Care 2010;33:2077-83.

28. Huang $\mathrm{Y}, \mathrm{Bi} \mathrm{Y}$, Wang W, et al. Glycated hemoglobin A1c, fasting plasma glucose, and two-hour postchallenge plasma glucose levels in relation to carotid intima-media thickness in Chinese with normal glucose tolerance. J Clin Endocrinol Metab 2011;96:E1461-5.

29. Kopple JD, Feroze U. The effect of obesity on chronic kidney disease. $J$ Ren Nutr 2011;21:66-71.

30. Das RK, Nessa A, Hossain MA, et al. Fasting serum glucose and glycosylated hemoglobin level in obesity. Mymensingh Med $J$ 2014;23:221-8

31. Selvin E, Crainiceanu CM, Brancati FL, et al. Short-term variability in measures of glycemia and implications for the classification of diabetes. Arch Intern Med 2007;167:1545-51.

32. Meigs JB, Nathan DM, Cupples LA, et al. Tracking of glycated hemoglobin in the original cohort of the Framingham Heart Study. $J$ Clin Epidemiol 1996;49:411-17.

33. Hanefeld M, Fischer S, Julius U, et al. Risk factors for myocardial infarction and death in newly detected NIDDM: the Diabetes Intervention Study, 11-year follow-up. Diabetologia 1996;39:1577-83.

34. Stuhlinger MC, Abbasi F, Chu JW, et al. Relationship between insulin resistance and an endogenous nitric oxide synthase inhibitor. JAMA 2002:287:1420-6.

35. Hotamisligil GS, Arner P, Caro JF, et al. Increased adipose tissue expression of tumor necrosis factor-alpha in human obesity and insulin resistance. J Clin Invest 1995;95:2409-15.

36. Mykkanen L, Zaccaro DJ, Wagenknecht LE, et al. Microalbuminuria is associated with insulin resistance in nondiabetic subjects: the insulin resistance atherosclerosis study. Diabetes 1998;47:793-800.

37. Cines DB, Pollak ES, Buck CA, et al. Endothelial cells in physiology and in the pathophysiology of vascular disorders. Blood 1998;91:3527-61.

38. Tarsio JF, Reger LA, Furcht LT. Molecular mechanisms in basement membrane complications of diabetes. Alterations in heparin, laminin, and type IV collagen association. Diabetes 1988;37:532-9.

39. Nelson RG, Bennett PH, Beck GJ, et al. Development and progression of renal disease in Pima Indians with non-insulin-dependent diabetes mellitus. Diabetic Renal Disease Study Group. N Engl J Med 1996;335:1636-42.

40. Fujita $\mathrm{H}$, Narita $\mathrm{T}$, Ito $\mathrm{S}$. Abnormality in urinary protein excretion in Japanese men with impaired glucose tolerance. Diabetes Care 1999:22:823-6.

41. Jensen JS, Feldt-Rasmussen B, Strandgaard S, et al. Arterial hypertension, microalbuminuria, and risk of ischemic heart disease. Hypertension 2000;35:898-903.

42. Bakker AJ. Detection of microalbuminuria. Receiver operating characteristic curve analysis favors albumin-to-creatinine ratio over albumin concentration. Diabetes Care 1999;22:307-13.

43. Eknoyan G, Hostetter T, Bakris GL, et al. Proteinuria and other markers of chronic kidney disease: a position statement of the national kidney foundation (NKF) and the national institute of diabetes and digestive and kidney diseases (NIDDK). Am J Kidney Dis 2003;42:617-22. 